\title{
'Whatever it means, you should have it": exploring digital literacies in arts education
}

\section{Copyright}

I hereby confirm permission to reproduce this work in the special e-learning issue of Art, Design and Communication in Higher Education.

\begin{abstract}
This paper examines both staff and students perspectives of using learning technologies within arts education in developing flexible, longitudinal support for digital literacies. Based on data collected at a small, specialist arts institution in the UK, the paper explores ways in which staff may consider students' use of technology in learning as well as how students themselves use technology in creative practices. In so doing, the paper considers the digital natives/ immigrants debate through a social constructionist lens to underscore how pervading assumptions about students' use of technology may influence ongoing support and ambiguous institutional culture.
\end{abstract}

\section{Keywords}

Digital literacies, digital natives, learning technologies, student engagement, social constructionism

\section{Introduction}

Students in creative disciplines, such as those studying Art, Design or Architecture, are required within their programmes to balance a combination of academic, information and digital literacies. The unique demands of composite modes of study - studio based learning as well as online and more traditional tutor-led scenarios - requires students to develop confidence in the underpinning principles common to all three literacy areas: adaptability, critical application, collaboration and solution-focused, creative use of educational technologies (see e.g. Lea 2004; SCONUL Working Group on Information Literacy 2011; Bawden 2001 for extensive discussion on attributes key to each area). 
However, students' use of technology in learning and teaching may not necessarily match existing confidence and competencies of everyday, personal use. As increasing criticism of reductionist concepts such as Generation Y, the supposedly technologically confident successors to Generation X, (Manuel 2002) and digital natives (Prensky 2001a, 2001b) attest, assumptions are often made on the part of institutions as to students' use of technology and the perceived ease of transferring principles from the personal domain to the academic (Beetham 2009; Cranmer 2006). Reaction to the digital natives debate now posits it as oversimplistic (Luckin et al 2009), and as harbouring potential for the interpretation of students' digital literacies to be stronger than they actually are (JISC 2009). As with both academic and information literacies, expectations of applying digital literacies within academic programmes must be made clear to students, both on joining their programme and as requirements change throughout each academic transition.

This paper reports on research conducted at a small, specialist arts institution in the UK. The research aims to collect staff and student perspectives on the role of technology in creative learning to contribute to progressive institutional strategy and better understand the disparate ways in which technology may influence creative practice and learning. In so doing, the project considers the social construction of the digital native in influencing pervading attitudes and institutional culture. In providing focus to discuss assumptions made about students' digital confidence, both staff and students were invited to share perspectives in order to facilitate more transparent opportunities for participation and collaboration and the creation of a tailored and contextually relevant staff development programme.

\section{Exploring digital natives as a social construction}

The well-established digital natives (Prensky 2001a) construct posits that those born into the digital age have an immersive command of technology, as opposed to those digital immigrants (born before 1980, according to Prensky), who are required to actively develop technological confidence and competence through adaptation. Digital natives allegedly share a number of defining characteristics, including an expectation of rapid information delivery, a pre-disposition to multi-tasking and accessing information in non-linear ways (Prensky 2001a, 2001b; Oblinger 2003). Bennet et al (2008) argue that the two-fold significance integral to the digital natives debate is that firstly, this discrete population with specific 
attributes exists, and that secondly, there is a significant mismatch between the expectations of the role of technology in learning between students and academic practitioners.

However, the fervour with which the debate has been received has in recent years been replaced by increasing criticism; a counter to the 'moral panic' with which Bennet et al (2008) argue has characterised attention to date. In suggesting a more disinterested, pragmatic approach, Bennet et al echo increasingly widespread criticism of the construct (Kennedy et al 2008). Indeed, the colonial native versus immigrant metaphor has been modified to reflect the existence of more transient and flexible residents and visitors (White and Le Cornu 2011).

For students, affiliation with the digital native 'tribe' may be less than straightforward. In considering the impact of the pervasive construction as part of contemporary educational discourse (contested or otherwise) it is perhaps useful to consider the digital native as a social construct. An integrative social constructionist perspective offers scope is one route to considering how knowledge and meaning are produced and shared in social contexts and through social processes of habitualisation and institutionalisation (Berger and Luckman 1966). In considering participation in education as a form of social interaction (Biesta 1998), a social constructionist perspective has a great deal to offer in unravelling potentially divisive concepts. From this perspective, Burr (2003) suggests that social constructionism's usefulness lies in its ability to:

'...caution(s) us to be ever suspicious of our assumptions about how the world appears to be. This means that the categories with which we as human beings apprehend the world do not necessarily refer to real divisions (p.3).'

Foucauldian interest in social constructionism considers its role in the classification and categorisation of people (McLaren 2002). Hacking (1999) refers to the interaction that takes place between people and their classifications as the 'looping effect', in that classifications become embedded within institutions, practices and language and are maintained through ongoing interactions. In the case of digital natives, it may be the case that the evolution and management of the construction is as presently influenced by Bennet et al's (2008) 'moral panic' suggestion, or, indeed, White and Le Cornu's (2011) Visitor/ Resident contestations as by Prensky's initial definitive description.

Harré (1993) suggests that through interactional positioning: 
'human beings become persons by acquiring a sense of self. But that can only occur in the social milieu in which they are already treated as persons by the others of their family and tribe' (p. 4).

From this perspective, belonging to the digital natives 'tribe' requires conditional characteristics of students in order to be acknowledged (such as those outlined by Prensky and Oblinger). Furthermore, ascription to the tribe would seem contingent upon integrative acceptance amongst peers and the academic community, and thus identification with a construction based, as are many aspects of identity, on sameness and difference (Lawler 2008); according to Jenkins (1996) having a social identity as well as an individual identity.

Sabat and Harré (1992) use social constructionism in explaining the negotiation of individual perceptions of self/ identity (singular or multiple) as well as those imposed/ assumed by others, particularly focussing on the role of agency and representation. Therefore, students may accept, reject or be ambivalent toward affiliation with the digital native construct. To date, little research has focussed on a student-driven interpretation of the construct, which constitutes a notable omission from related literature. The research described in this paper aspires to inform future discussion in this area by sharing student observations of their own digital confidence and preferences in creative learning.

\begin{abstract}
About the research
The data on which this paper are based comprise staff responses to an opt-in web-based survey and the transcripts of two student focus groups. The intent is not to construct a reductive and simplistic picture of the institution's practices and preferences, but rather to highlight disparate examples from across different creative areas to facilitate improved understanding of the multiple, and often unconscious, ways that technology may influence learning in the creative arts.
\end{abstract}

This research had a number of primary drivers: firstly, an increasing strategic interest at the institution where the research was carried out in ensuring that the blended learning framework was robust, forward looking and responsive to student expectations; secondly, to provide a focus on student-centred perspectives of the role of technology in creative learning in order to influence clear and shared expectations; and thirdly, to contribute to an iterative, 
participatory and tailored staff development programme. Furthermore, two broad research questions guided the data collection and analysis:

1. In what ways might staff perceptions and assumptions about students' use of technology in creative learning influence institutional provision?

2. In what ways might students' use of technology shape their creative practice/ selves?

In spring 2012, all staff across the institution were invited by email to respond to a short web survey about the use of learning technologies. 70 staff from across the institution responded: $66 \%$ of whom were academic or academic related staff; $25 \%$ of whom were administrative staff; $9 \%$ of whom were technical or IT staff. The questionnaire comprised a mix of closed and open-ended questions (agree/ disagree, likert responses and open-ended text boxes) about use of technology throughout the institution, preferred tools, etc. A key section asked staff about their perspectives of students' engagement with and use of technology in learning. The responses to these questions form the basis for part of the staff perspective presented in this paper.

In addition, two focus groups were conducted with students in the students' union. All students were emailed about the events and invited to participate, with 6 attending each. The discussions were facilitated by myself and consent to make an audio recording of the discussion requested from each participant. There was an additional note-taker/ co-facilitator and both discussions were transcribed. The transcriptions of the two focus groups are analysed in presenting the student perspective.

The data collected from the staff survey has been collated into descriptive statistics to give an overview of technological usage and perspectives. In addition, some extracts from the free text responses have been used to illustrate issues arising from practice observations. The analysis of the transcripts from the student focus groups takes an approach that borrows from grounded theory research's constant comparison analysis (Glaser 1978, 1992; Glaser and Strauss 1967; Strauss 1987). This approach follows a three stage process in which firstly, open coding identifies sections of related text and adds description, secondly, the sections of text are joined together in categories, and in the third stage, the categories are developed into themes. Leech and Onwuegbuzie $(2007,2008)$ have argued that this approach is particularly appropriate for focus group transcripts in identifying recurring issues from accounts of extended and co-authored talk. 


\section{About the institution}

Learning technologies have been an integral part of learning and teaching practices at the institution where the research was carried out for a number of years. In addition to a centrally administered Virtual Learning Environment (VLE) through which students access academic course information, tutors make use of a variety of media and technologies which extend opportunities for learning beyond the studio. Increasingly, in line with an expansion in the use of non-mainstream knowledge and discourses as part of internationalisation and massification of education in recent years (Eijkman 2009), collaborative web 2.0 and mobile technologies are used to facilitate creative learning networks. The use of blogs and wikis as collaborative learning spaces, as well as connective social media such as Twitter, Facebook and media repositories such as Flickr and Vimeo have also increased in use. There are a number of virtual interdisciplinary communities (some curated by students) affiliated with the institution where information about events, exhibitions or creative works are shared.

At the institution where the research was carried out, a number of initiatives already exist to facilitate this scaffolding of students' use of technology in learning. For example, 'IT Twilight Classes' offer a programme of opt-in, after-hours software workshops where students can develop or enhance their confidence in a particular area. Workshop materials are made available through the VLE so that if students are unable to attend they can access resources at a time that is convenient to them, and on a repeat basis. Also, the Webtastic! VLE course contains a diversity of resources (podcasts, walk through guides, videos, links) to help students develop and manage their own web presence. In addition, the InfosmART information literacy resource, which has recently been made available for re-use by other arts-based institutions under a Creative Commons licence, offers support on using evidence in academic work.

Each of these initiatives is aimed at providing explicit guidance in helping students develop digital literacies. For Gillen and Barton (2011), digital literacies refer to 'constantly changing practices through which people make traceable meanings using digital technologies' (p. 9). Such meaning-making is clearly key within creative education in encouraging expression, reflection, autonomy and lateral sense making. As such, embracing digital technologies as part of the holistic learning experience is vital in enabling students to research, develop and articulate ideas in a variety of innovative multimedia formats. The influential DIAL (Digital Integration in Arts Learning) project at the University of the Arts is an existing example of 
highlighting the importance of digital literacies throughout education in the Arts, with specific focus on improving graduate employability through sustained cultural change.

\section{Staff perspective}

As part of the staff survey, colleagues were asked about their use of a diversity of tools that they may or may not have used in teaching. Table 1 below summarises responses to this question, in which staff were invited to select multiple answers from prompts.

Unsurprisingly, visual media (moving and static) featured strongly, as did the connectivity of hypermedia and the institutional hub of the VLE.

\begin{tabular}{|l|r|r|}
\hline Q. Which technologies/ media do you use for educational purposes? & \% & n (64) \\
\hline Audio & $39.7 \%$ & 25 \\
\hline Blogs & $49.2 \%$ & 31 \\
\hline Hyperlinks to external content & $69.8 \%$ & 44 \\
\hline Images/ photographs & $79.4 \%$ & 50 \\
\hline Microblogging (e.g. Twitter) & $14.3 \%$ & 9 \\
\hline Podcasts & $15.9 \%$ & 10 \\
\hline Social media (e.g. Facebook) & $22.2 \%$ & 14 \\
\hline Video & $54.0 \%$ & 34 \\
\hline VLE & $76.2 \%$ & 48 \\
\hline Wikis & $15.9 \%$ & 10 \\
\hline
\end{tabular}

Table 1: Staff use of technologies/ media in teaching

The survey also asked staff which attributes they considered important in students' use of technology. This question was intended to seek perspectives on learner attributes as opposed to responses which may be related to specific software packages or technologies, and the response options were informed by principles and attributes associated with models of digital literacy (Gilster 1997; JISC 2012). These responses are summarised in Table 2.

\begin{tabular}{|l|r|r|}
\hline $\begin{array}{l}\text { Q. In terms of using technology for learning, what skills/ competencies do } \\
\text { you think it is important for students to have? }\end{array}$ & $\mathbf{~ n ~ ( 5 0 )}$ \\
\hline Adaptability & $72.0 \%$ & 36 \\
\hline Autonomy & $50.0 \%$ & 25 \\
\hline Collaboration & $42.0 \%$ & 21 \\
\hline
\end{tabular}




\begin{tabular}{|l|r|r|}
\hline Communication & $62.0 \%$ & 31 \\
\hline Creativity & $50.0 \%$ & 25 \\
\hline Critical skills & $58.0 \%$ & 29 \\
\hline Information retrieval & $74.0 \%$ & 37 \\
\hline Problem solving & $54.0 \%$ & 27 \\
\hline Technical competence & $62.0 \%$ & 31 \\
\hline
\end{tabular}

Table 2: Staff perceptions of learner attributes as regards using technology in learning

Interestingly, staff privileged transferrable attributes such as adaptability and information retrieval over specific examples of technical competence. An autonomous perspective was also more strongly supported that a collaborative one, potentially reflecting the focus on the self in creative learning and practice.

In addition, perspectives were also sought on how staff perceived students' confidence in using technology when joining their programme of study. In response to the question 'In your experience, do students join (the institution) with adequate existing skills/ confidence in using technologies for educational purposes?', 41.4\% (24 respondents where $\mathrm{n}=58$ ) answered yes, $19 \%(n=11)$ answered no, and the remaining 39.7\% $(n=23)$ were unsure. This highlighted an interesting ambiguity as regards staff perceptions of students' digital confidence: though many considered students highly competent users of technology, an equal amount were unsure if the associated skills existed at the beginning of the Higher Education learner journey.

This ambiguity was further nuanced in some of the open-ended qualitative text responses which identified enduring complexities. Whilst some described how their students were 'at the cutting edge of using modern technology to communicate' or confident that technology was 'in their blood', others acknowledged the need for continued support in developing students' digital confidence. Given the prevalence of digital modes of communication and information exchange in everyday life and students' futures, many respondents agreed that technology played a crucial role in lifelong learning and students' future practice, describing it as 'crucial', 'essential', 'central' and 'key',

As two respondents commented: 
"It's essential for students to develop confidence using technology as it plays a vital role in their full participation in their course, and will continue to do so in their lives beyond HE."

"As computers are used more and more in the modern world I feel that it is important for students to be able to use them competently. They should not be afraid to try new and different software."

In this context, the role of the institution is providing appropriate, relevant support and a stable infrastructure was highlighted in terms of both the technology available and the digital literacy of staff. The need for the institution to provide a robust technological infrastructure (software and hardware) in embedding technology in learning was noted:

"...if the tech we provide is not up to scratch they (students) simply do not use it and instead use other solutions."

This is interesting given the debate around personal versus academic use of technology, and the fact that students may have preferred solutions in either domain that may or may not be integrative. Another member of staff commented on this by noting:

"I think students mainly have high levels of confidence in using social media technology but low confidence/competence in using technology for learning"

In light of this potential for students' confidence in personal technological use, a staff member noted the need for colleagues to keep abreast of technological trends and usage to inform ongoing learning and teaching activities. The institution's intent to provide opportunities for staff development and mechanisms for practice sharing is intended to offer a space for staff to reflect on student-driven use of technology in learning and share existing examples from across the institution. One staff member noted:

"Most students are probably more competent than many of staff; it's perhaps more important that staff can keep up as use of technology is now ubiquitous."

\section{Student perspective}

As noted, two student centred focus groups were held at the beginning of the academic year 2012/13. Students were invited to attend via an opt-in email, posters and flyers and the 
discussions were held in the institution's student union during lunchtime. A total of 12 students attended two discussion groups, 6 in each. Discussions were guided by a series of prompts, including stimulus questions such as:

- In previous learning, what types of technology have you used (hardware and software)?

- Do you (or have you) used mobile devices (smartphones, tablets) as part of learning?

- Do you use social networking? If yes for personal or creative reasons? Both?

- Have you heard the term 'digital native'? If yes, is this something you identify with?

Issues raised in the discussion groups reinforced complexities associated with perceptions of students' use of technology in learning. Students shared contrasting and diverse perspectives on the role that digital tools played in their learning and creative practices, and, echoing staff perspectives, highlighted the importance of the institution in providing a robust technological infrastructure and in helping to clarify the purpose of differing technologies in learning. Students noted the usefulness of the immediacy of responsive support to software and hardware queries with direct access to staff in the library, as well as to the scheduled IT Twilight classes.

Students who took part in discussions noted huge variations in access and ownership of mobile technologies, from non-existent to immersive engagement. In induction sessions during the beginning of the academic year 2012/13, of 478 students, 320 owned smartphones (as a proxy for mobile engagement in this context) (67\%). Whilst there may be a presupposition that most if not all students may have access to the use of a smartphone and thus portable access to immediate information, for a third of incoming students this was not the case. Whilst mobile pedagogies are an area that the institution is keen to explore, encompassing the use of tablet and other handheld devices as well as smartphones, this will be done as an enhancement or alternative to principal blended routes. In this way, the flexibility offered by mobile technologies provides scope for learner choice and autonomy.

\section{Technology as situated process}

In setting the context for discussion, students were asked about their use of technology in learning. Students were initially hesitant in noting specific software packaged, in keeping Oblinger and Oblinger's (2005) observations of vagueness in identifying particular technologies. Also, as per Oblinger and Oblinger's research, the students spoke in terms of process and outcome, of the creative journey and what the technology allowed them to 
achieve as opposed to the focussing on the technology itself. For one Fine Art Photography student this process was about protection, and having more scope to preserve the stages of her work as opposed to risking 'ruin':

"I'm more of a digital person, because I tend to ruin things. Cos in analogue photography you just have much more stages and you can actually ruin what you've done...you can go wrong at more stages...but it really depends on the quality and feeling you want to achieve."

The student also mentioned how the digital process was well suited to her specialism (selfportraiture) as 'it's much harder to locate yourself inside a frame once you're doing analogically'. Another Photography student conversely highlighted her preferences for limited digital input, due to the restrictions of having to be computer based. She remarked:

"I'm a big film person. And I think that's about for the process for me - like I don't like five hours in front of a computer screen and feel very different about that than, like, five hours in the dark room."

This sense of practice in the creative learning environment was referred to by another student who saw technology as a way of providing peer cohesion, company and support. She privileged the importance of the co-created learning experience as opposed to the potentially isolating experience of independent self-study, and again cited her use of technology as instrumental in this:

"Just being with someone else in the room, people working...in this work environment, so you're more productive. I stay, like, one hour...two hours after teaching finishes because we have a full curriculum... and I choose to stay there several hours sometimes just because there are people there..."

\section{Connectedness and culture}

Differing perspectives emerged, perhaps unsurprisingly, between students' prior cultural experiences of using technology in learning. Contrasting perspectives were offered by two exchange students (one spending time at the institution where the research was conducted and one who had recently returned from an exchange) whose recent experiences offered two differing perspectives. The incoming exchange student spoke about having grown up in a rural community where connectivity was limited and technology not embraced. 
"I went to school in X, which is a really small town and a lot of the people I went to school with had no knowledge of technology, they just didn't know how to use it... a lot of them refused to. And that was weird, because they just didn't use it at all, everything was by paper. And that was really interesting - I think it's really important to have the online aspect..."

Such a memorable cultural perspective would seem to have a discernible effect on this student's engagement with technology and preferred modes of practice (for example, in her preference of the analogue production process to digital), alluding to the impact of Bourdieu’s (1990) ‘habitus' on her continued learning and creative practice.

Conversely, the student who had recently returned from international study spoke about being part of a vibrant online community, where the institutional infrastructure allowed for students' creative work to be showcased and distributed. Students in the group discussed this as a positive aspect of study, to be able to share their work (or not) according with their own preferences. In this context, other students spoke about the role of social media such as Facebook in promoting, or limiting, an online presence. One student noted that although this was being used as a form of community with her class, the blurred boundaries of sharing her academic content with a wider network made her uncomfortable in favour of doing so

"We're using Facebook, we share with the class, like... a separate website and our group. But I don't want to share my work with other people... with different friends. For example, I don't really want to show something that is, I don't know... deeper."

These perspectives illustrate divergences in ways that students choose to use connective media. These preferences are influenced by students' background, extended network of practice and creative self-understanding. Within this broad, differentiated continuum of use (Kennedy et al 2008), students are able to exercise autonomy in bounding their interactions and networks, depending on technological interactions and the nature of complementary and integrated platforms.

\section{Digital natives?}

Students were asked about their awareness and interpretation of the term 'digital native' as part of discussions. Despite none of the students having heard the term, two students said that 
they would consider themselves to be digital natives, and that it was a description that resonated with them. Other students described it as 'a strange term' or 'a weird concept', and one student commented on its limiting potential:

"I think to assume anyone born would automatically know how to use one form of technology or maybe prefer it to an analogue process is slightly jarring..."

In discussing the time-bound definition of being born post 1980, as per Prensky's description, another student raised concerns about the efficacy of making sweeping generalisations based purely on age:

"Yeah, I mean my idea of those terms is that it's kind of dangerous to assume that anyone born past 1980 will automatically be able to use technology... and also, you can't put everything digitally... I just like people. Like, going to self-service checkouts at the supermarket - it irritates me that there's a robot that's taken somebody's job and to some degree in the library...the self check out, in some respects it speeds it up, but you can't beat a bit of paper and a person..."

Another student transposed some of the problematic aspects of the digital native construct to conceptualising digital literacies. Students were less able to define what this might actually mean for them, and were quick to point out the context dependency of a definition.

'It's a strange one. I've heard of the term' digital literacy' but it completely depends on what you're using or what... what it is. Just because its digital doesn't mean it's user-friendly. But I mean ...I know you need to title things, you need to give things a snappy heading and I would call myself digitally literate...but again, it depends. Stick me in front of a certain programme and I'm lost. But then again I've probably got the understanding to work out how to solve the problem, you know maybe around file menus. So I mean, within half an hour I could get my head around something...but again to assume that that's the case for the majority... you can't really do that."

This student highlighted the importance of the underpinning attributes as opposed to software-specific knowledge, and whilst confident that he could employ these skills was unsure that this was a universal truth for his peers. Another student also highlighted that they could likewise understand the concept of digital literacy, but also found it problematic. However, as a graduate attribute, the student acknowledged the importance of developing digital confidence in this context over the course of study: 
"I do think it's a skill in college, you know, something you should leave with...or at university. Whatever it means - you should have it..."

This reference to the vagueness of 'whatever it means' encapsulates well the ambivalence that Eshet-Alkalai's (2004, p. 94) refers to in the suggestion that 'indistinct use of the term causes ambiguity, and leads to misunderstanding, misconceptions, and poor communication'. The vagueness was countered by students' request for clarity and consistency, in, for example, guidance on using the library catalogue and in course organisation in the VLE. In discussing the latter, one student highlighted importance of staff awareness under the auspices, too, of 'literacy':

"And it's something that should expand to the tutors to make sure that they're VLE literate...so there's a kind of set way of doing things, cos it is sporadic in terms of folders in different departments. But I mean obviously a lot of the tutors will be, uh...immigrants to technology...so that's another reason to make sure that everyone's on the same page...it's just a massive page."

\section{Discussion}

Both staff and student perspectives highlighted ambiguity as regards perceptions of students' use of technology in learning. Staff were unsure in their responses to the survey of levels of students' digital confidence in learning, and students had difficulty in accepting the 'snappy headings' related to digital natives or digital literacies. Interestingly, however, this did not mean that the terms were rejected; although conceptually problematic, some of the students stated that they did consider themselves digital natives or digitally literate. What was contested was the reductive nature of the restrictive definitions based on age alone.

In returning to the research questions set out earlier in this paper, a number of factors from the staff and student perspectives can be considered.

1. In what ways might staff perceptions and assumptions about students' use of technology in creative learning influence institutional provision?

Despite ongoing engagement with and commitment to using technology as an embedded part of learning and teaching, staff conceptions of students' digital confidence remain vague. Whilst some ascribe to the existence of those digital natives who have technology 'in their blood' others recognise that confidence in using technology for pedagogical purposes may be developmental. In light of plans to improve opportunities for staff to participate in collegiate, 
cross-institutional communities of practice (virtual or face-to-face) to share perspectives, possibilities to contest vagueness through discussion, collaboration and experimentation will offer opportunities for the exchange and enrichment of practice. Staff also recognised the role of the institution is providing access to robust and appropriate software and hardware if student engagement is to be assured. Again, feedback from and continued dialogue with students will contribute to awareness of usage trends and infrastructural requirements.

2. In what ways might students' use of technology shape their creative practice/ selves?

Students discussed the need for a more fluid, contextually dependent understanding of interactions with technology, based on personal choice, selected interactions, access to community and enactment of autonomy as opposed to definable and compartementalising demographics such as age. Students discussed the usefulness that technology afforded them in terms of creative preservation and process, choice of media and mode, connectivity and peer support. Some also recognised their ability to transfer principles of use from one software package to another, under the auspices of grappling with the tenets of digital literacy, 'whatever it means'. The co-existence of analogue and digital techniques was endorsed by students in examining their practice and considering their preferences.

\section{Conclusions}

A flexible, mutably typology of use and engagement with learning technologies based on context-dependent interactions allows for less division and compartmentalisation, and posits that potentially everyone can and does interact with technology in some form. Such an inclusive perspective offers technology users (in this case staff and students) the scope to change roles and control interactions and process as opposed to being ascribed a bounded and potentially passive identity. All those who engage in such digital navigation may enact autonomy in digital interactions, information retrieval and critical application or transference of technological knowledge and experience. As notions of digital literacy pervade throughout the lifecourse, so too does an ability to navigate digital resources as one migrating from learning episode to functional task to reflection.

Navigation between, rather than into, technologies is part of a flexible, customisable and vibrant continuum, contingent upon diversity, difference and autonomy as opposed to isolated, contradictory and compartmentalised roles. Variances in process, subject specificity, 
culture, context and access to technology inform learner choices and preferences in medium and thus have an undeniable effect on the creative process. For the institution where the research was conducted and the ongoing development of collaborative staff development being considered implemented, participate values of transience and autonomy are encouraged in finding engaging ways of supporting democratic learning. 


\section{References}

Bawden, D. (2001). Information and digital literacies: A review of concepts. Journal of Documentation, 57 (2), pp. 218-259

Beetham H. (2009) Academic values and web cultures: points of rupture. Paper to ESRC Literacies in the Digital University seminar, Friday 16 October 2009, Edinburgh University

Bennet, S. , Maton, K. and Kervin, L. (2008) The 'digital natives' debate: A critical review of the evidence. British Journal of Educational Technology, 39 (5), pp. 773-964

Berger, P. L. and Luckman, T. (1966) The social construction of reality: A treatise in the sociology of knowledge. New York, Random House

Biesta, G. (1998) Pedagogy Without Humanism: Foucault and the Subject of Education. Interchange, 29 (1), pp. 1-16

Bourdieu, P. (1990) The Logic of Practice. Cambridge, Polity

Burr, V. (2003) Social constructionism. London, Routledge

Cranmer S. (2006) Children and young people's uses of the Internet for homework. Learning, Media and Technology, 31, pp. 301-316

Eijkman, H. (2009) Using Web 2.0 to decolonise transcultural learning zones in higher education. Campus-Wide Information Systems, 26 (3), pp. 240 - 255

Eshet-Alkalai, Y. (2004) Digital literacy: A conceptual framework for survival skills in the digital era. Journal of Educational Multimedia and Hypermedia, 13 (1), pp. 93-106

Gillen, J. and Barton, D. (2011) Digital literacies: A Research Briefing by the Technology Enhanced Learning phase of the Teaching and Learning Research Programme. TLRP-TEL

Gilster, P. (1997) Digital Literacy. New York: Wiley

Glaser, B. G. (1978) Theoretical sensitivity. Mill ValleySociology Press

Glaser, B. G. (1992. Discovery of grounded theory. Chicago: Aldine

Glaser, B. G., and Strauss, A. L. (1967). The discovery of grounded theory: Strategies for

qualitative research. Chicago: Aldine 
Hacking, I. (1999) The Social Construction of What? Harvard University Press, Harvard Harré, R. (1993) Social Being. $2^{\text {nd }}$ edition, London, Wiley-Blackwell Jenkins, R. (1996) Social identity. London, Routledge JISC (2009) Work-with-IT. JISC Study into Evolution of Working Practices. Final Report. JISC

JISC (2012) Digital literacy anatomised: access, skills and practices. Available from: http://bit.ly/jiscdiglit

Kennedy, G. E, Judd, T. S, Churchward, A. Gray, K. and Krasue, K. (2008) First year students' experiences with technology: Are they really digital natives? Australasian Journal of Educational Technology, 24 (1), pp. 108-122

Lawler, S. (2008) Identity: Sociological perspectives. Polity Press: Cambridge

Lea, M. (2004) Academic literacies: a pedagogy for course design. Studies in Higher Education, 29 (6), pp. 739-756

Leech, N. L., and Onwuegbuzie, A. J. (2007) An array of qualitative data analysis tools: A call for qualitative data analysis triangulation. School Psychology Quarterly, 22, pp. 557-584 Leech, N. L., and Onwuegbuzie, A. J. (2008) Qualitative data analysis: A compendium of techniques for school psychology research and beyond. School Psychology Quarterly, 23, pp. $587-604$

Luckin, R., Clark, W. Graber, R, Logan, K. Mee, A. and Oliver, M. (2009) Do Web 2.0 tools really open the door to learning? Practices, perceptions and profiles of 11-16-year-old students. Learning, Media and Technology, 34 (2), pp. 87-104

Manuel, K. (2002) Teaching information literacy to Generation Y. In Durisin, P. ed. Information literacy programs: successes and challenges. New York: Hawthorn Information Press, pp. $195-218$

McLaren, M. (2002) Feminism, Foucault, and Embodied Subjectivity, State University of New York Press, Albany

Oblinger, D. (2003). Boomers, Gen-Xers and Millennials. Understanding the new students. EDUCAUSE Review, 38(4), pp. 37-47 
Oblinger, D., and Oblinger, J. (2005). Is it age or IT: First steps toward understanding the net generation. Educating the net generation, 2(1-2), pp. 20

Prensky, M. (2001a) Digital natives, digital immigrants. On The Horizon. 9 (5), pp. 1-6

Prenksy, M. (2001b). Digital Natives, Digital Immigrants, Part II. Do they really think differently? On the Horizon, 9 (6)

Sabat, S. R. and Harre, R. (1992) The Construction and Deconstruction of Self in Alzheimer's Disease. Ageing and Society. 12, pp 443-461

SCONUL Working Group on Information Literacy (2011) The SCONUL Seven Pillars of Information Literacy Core Model For Higher Education. Available online:

http://www.sconul.ac.uk/sites/default/files/documents/coremodel.pdf

Strauss, A. (1987). Qualitative analysis for social scientists. Cambridge: University of Cambridge Press

White, D.S. and Le Cornu, A. (2011) 'Visitors and Residents: A New Typology for Online Engagement', First Monday, 16 (9). Available online:

http://firstmonday.org/htbin/cgiwrap/bin/ojs/index.php/fm/article/view/3171/3049

\section{Total word count including references}

6,030 